\title{
In the Era of Social Media
}

\section{Is it time to establish a code of online ethical conduct for healthcare professionals?}

\author{
Amal A. Al-Balushi
}

$$
\text { هل حان الوقت لوضع مدونة للسلوك الأخلاقي لاستخدام الإنترنت للعاملين في التواصل بحال الرعاية الصحية؟ }
$$

$$
\text { أمل أحمد البلوشية }
$$

\begin{abstract}
Social media is becoming an invasive part of the lives of many professionals including those in the healthcare field. One of the countless implications of such an invasion is how the healthcare professional's engagement with social media affects the traditional doctor-patient relationship. The online presence of professionals should be carefully self-monitored as it affects the individual's reputation and society's perception of their profession. Therefore, the contents of public and personal accounts must differ according to their purpose. In the public eye, conflicts of interest must be declared and scientifically-based medical advice should be clearly differentiated from experience-based advice, personal opinions or commercial advertisements. Online doctorpatient relationships risk the privacy of patients as well as the personal privacy of the healthcare professional. Personal accounts created for friends and family should be kept separate from public accounts created for educational, professional or commercial purposes. Published educational material should be clearly differentiated from commercial material so that it is easier for the public to make an informed decision. This paper proposes a code of online ethical conduct to be implemented in Oman.
\end{abstract}

Keywords: Codes of Ethics; Social Media; Health Personnel; Privacy; Confidentiality; Conflict of Interest; Physician-Patient Relations; Oman.

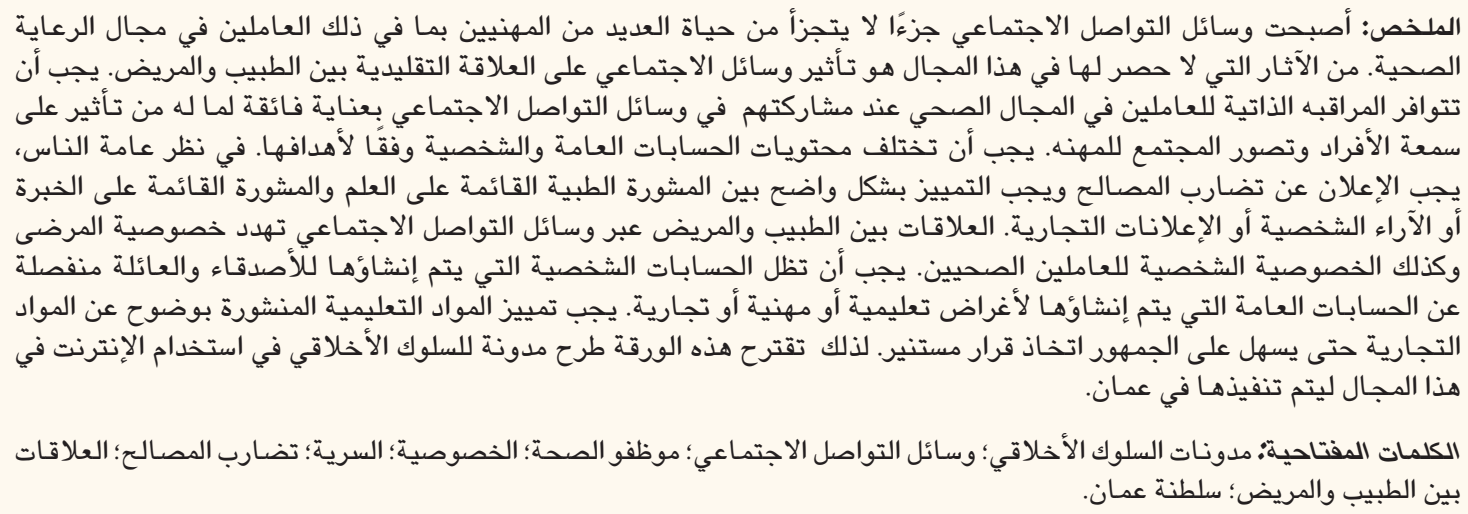

\section{$\mathrm{T}$} HE USE OF SOCIAL MEDIA HAS SIGNIFICANTLY reduced personal privacy of individuals. ${ }^{1}$ Healthcare professionals are no exception as they often use social media as a marketing tool for their services, a way to provide health education, for research or as a socialisation tool. ${ }^{2}$ Use of social media by professionals carries some risk as shared posts can be permanent. ${ }^{3}$ Since the personal life of a healthcare professional can affect his or her professional life, a number of countries have developed guidelines for the use of social media by healthcare professionals. ${ }^{4,5}$ To date, there are no guidelines in Oman for the use of social media by healthcare professionals.
When healthcare professionals and patients interact on social media, it is often initiated by patients. ${ }^{6}$ While discussions regarding medical issues in online forums do have considerable educational value, such interactions may carry a risk of misconduct. A study done in the USA showed that the most common forms of online-professionalism violations included inappropriate communications with patients-specifically internet prescribing, misrepresentation of credentials and sexual misconduct.?

The medical profession deals with the health and lives of people and has traditionally been respected and trusted by the public. This positive view is essential 
as patient compliance and prognosis are dependent on such trust. Healthcare professionals have significant influence over their patients which should not be misused for their personal benefit. Engaging with a patient online can affect the doctor-patient relationship and may lead to personal or even romantic relationships. ${ }^{8}$

\section{Online Professional Image}

The image and behaviour of healthcare professionals outside of work should be a personal matter. However, their public image outside of work-online or otherwise-becomes a professional matter as it represents their profession. Society expects that its healthcare professionals be role models that can be emulated, that are healthy and fit, free from addictions, not prone to extramarital affairs and generally free from behavioural issues. It is likely that patients might have less faith in a healthcare professional's abilities when they are not capable of solving their own problems. As a result of the long-term and easy availability to an online personality and by the nature of their profession, healthcare professionals have an inherent influence on society and are therefore obliged to lead by example. This responsibility is inherent to the medical profession, as well as any other professions which can influence people's opinions, ideas, thoughts and behaviours.

The medical profession requires some commitment that extends to the private lives of those working within it, as the public scrutinise these professional's online behaviour. The medical profession has an influence on society in terms of what is healthy and not healthy regarding products, practices and lifestyles. People expect healthcare professionals and providers to adhere to the advice that they give.

Describing patients or colleagues in a negative light in online forums affects current and future doctorpatient relationships. ${ }^{9}$ Social media should be used positively to promote health and to set an example of online professional behaviour. ${ }^{10}$ The online image of healthcare professionals may provoke an unconscious judgment which may affect the belief in the profession and hence adherence to any proposed treatment plans. The online image can also affect the professional's reputation as well as the reputation of the profession itself. ${ }^{3,7}$ Medical schools should begin by teaching medical students about the consequences of poor online behaviour. ${ }^{10}$ While senior healthcare professionals usually concentrate on formal teaching and training activities, they may forget that informal teaching is continuously occurring through the behaviours they model. Therefore, senior healthcare professionals should actively act as role models for junior healthcare prof- essionals. ${ }^{11}$ Additionally, inappropriate comments or photographs of compromising behaviour on social media forums can not only tarnish the image of the professional but also have an impact on their affiliated institution's reputation. ${ }^{12}$ Furthermore, online posts are difficult to delete if they are shared and become permanent, thereby staining a medical professional's record. ${ }^{3,13}$

\section{Social Networking, Confidentiality and Conflicts of Interest}

Social networking is a very useful way of communicating with the public. Healthcare professionals can use social media positively to follow and support their patients and to increase awareness and educate the public about health-related issues. ${ }^{14,15}$ However, the public needs to be aware of the high possibility of misinformation on social media channels. ${ }^{15}$ Online information may only be partially accurate and not fully represent an individual's case. ${ }^{16}$ Even factual information can cause confusion or unnecessary anxiety; for example, an individual with iron-deficiency anaemia may think that they have cancer upon reading 'fatigue' as a symptom of cancer. Fake accounts, which present false credentials or profiles that pose as someone they are not by using a real doctor's name, are harmful as they disseminate inaccurate information which can harm patients' health and affect public trust in the profession. Moreover, society needs to learn how to differentiate between opinion, advertisement, experience-based advice and scientific evidence-based advice.

Social media can violate one's privacy and can be used to violate other's privacy and confidentiality. ${ }^{2}$ Professional social media accounts should not be used to share details of one's personal life with the public. While healthcare professionals should certainly not live in isolation, it is recommended that personal accounts not be shared with the public. If the account is made accessible to the public, content on personal accounts should be carefully curated. Alternatively, a professional can have two accounts, one personal and private and another professional and public. The username of personal accounts should not include a professional title such as 'Dr' or professional credentials. It is advisable to set the privacy settings to 'high' on personal accounts. ${ }^{3}$ However, one should still be cautious with content in general as privacy cannot be guaranteed. A healthcare professional should not post anything unless they would be comfortable if that content went public. ${ }^{16}$

Doctors and healthcare providers can ethically use social media to communicate with colleagues, for public education, to advertise their services or to pro- 
mote products that they think would be beneficial. ${ }^{2}$ However, it would be unethical to promote a specific pharmaceutical product or company. Healthcare providers are supposed to promote the health of the public; however, it is assumed that promoting specific products is more about the promotion of personal wealth. This also applies to healthcare professionals who run their own businesses in the pharmaceutical or cosmetic industry.

Medical advice must be distinguished from marketing by full disclosure. Whereas in classic print media, advertorials in magazines stated in small print that they were selling something, in this new era of social media, this type of disclosure is often overlooked. Moreover, healthcare professionals need to disclose any conflicts of interests when marketing a product. If such a disclosure is not made, a conflict of interest might arise as marketing could be mistaken for medical advice. Ultimately, disclosure alone may not be sufficient and any conflict of interest should be avoided by healthcare professionals not engaging in marketing in the first place.

Regarding confidentiality, using social media channels to share patient cases might harm the patient and expose their identity. ${ }^{9}$ Publicly sharing photos of patients for educational or marketing purposes or with other professionals for consultations is unethical as it jeopardises the patient's confidentiality and privacy unless written consent is provided by the patient; this is regardless of whether the photograph contains identifying information or not. ${ }^{17}$ Not adhering to such guidelines have resulted in some healthcare professionals losing their practicing license and/or career. ${ }^{17}$ Written consent in such cases is of vital importance to protect the patient's privacy and the physician from liability as such photographs are difficult to remove by the non-consenting patient once published online and shared. ${ }^{17}$ Accessing patient information online poses another issue for healthcare providers. Psychiatrists can use social media profiles of their patients to gain additional collateral history as some patients cannot provide a reliable history. ${ }^{18}$ Neurologists or intensive care unit professionals can also use social media to find the profiles of trauma or comatose patients. Although such use could aid in diagnosis, it should not be done without the patient's or next of kin's consent.

\section{Therapeutic Doctor-Patient Relationship}

Accepting requests from patients to connect online may risk the integrity of the therapeutic relationship.,19 It can also risk exposing personal information about the physician that would not be revealed in a regular doctor-patient relationship. ${ }^{9}$ Therefore, it is advisable not to accept online requests from patients on any social media platform as this might lead to power imbalances in the therapeutic relationship. The physician can discuss why accepting such communications is unethical and can affect the therapeutic relationship with the patient during an appointment. ${ }^{19}$ On one hand, some patients might feel more at ease consulting a general practitioner online. ${ }^{20}$ On the other hand, the physical examination, which is an important part of the medical consultation, cannot be done online and therefore online consultation is considered an unacceptable clinical practice. ${ }^{20}$ In addition, the source and eligibility of the person providing medical recommendations via social media can be difficult to verify. ${ }^{21}$ Furthermore, such advice or recommendation did not undergo a peer-review process. ${ }^{22}$ Because of these reasons, online advice should be given and received with caution.

\section{Conclusion}

The use of social media networks by medical professionals and its associated ethical dilemmas necessitates its regulation. Social media use by healthcare professionals can have implications on the doctor-patient relationship, public trust in the profession as well as possible litigation. Each individual should take responsibility and accountability for their posts on social media platforms. If a medical professional would like to have a personal account, then they should not be identifiable as a medical professional in that account. In addition, it is advisable to act modestly even in personal accounts. Accounts created for medical purposes, for example, to educate the public, raise awareness about health-related issues or advertise for a licensed private practice, should provide clear medical identification. Furthermore, such public accounts should be managed carefully and the material posted should be presented appropriately. Interactions with patients are discouraged and should never take place via personal accounts. Healthcare workers should be taught and encouraged to act professionally; it is fellow professionals that should establish a norm regarding online behaviour that others may then follow. Establishing a code of online ethical conduct in Oman would help to draw a line between professional and non-professional online behaviour.

\section{References}

1. Senthil Kumar N, Saravanakumar K, Deepa K. On privacy and security in social media - A comprehensive study. Procedia Comput Sci 2016; 78:114-19. https://doi.org/10.1016/j. procs.2016.02.019.

2. Milton CL. Ethics and social media. Nurs Sci Q 2014; 27:283-5. https://doi.org/10.1177/0894318414546417. 
3. Rouprêt M, Morgan TM, Bostrom PJ, Cooperberg MR, Kutikov A, Linton KD, et al. European Association of Urology (@Uroweb) recommendations on the appropriate use of social media. Eur Urol 2014; 66:628-32. https://doi.org/10.1016/j.eururo.2014.06.046.

4. Federation of State Medical Boards. Social media and electronic communications. From: http://www.fsmb.org/siteassets /advocacy/policies/social-media-and-electronic-commun ications.pdf Accessed: Oct 2019.

5. British Medical Association. Social media guidance for doctors. From: https://www.bma.org.uk/advice/employment/ethics/soc ial-media-guidance-for-doctors Accessed: Oct 2019.

6. Bosslet GT, Torke AM, Hickman SE, Terry CL, Helft, PR. The patient-doctor relationship and online social networks: Results of a national survey. J Gen Intern Med 2011; 26:1168-74. https://doi.org/10.1007/s11606-011-1761-2.

7. Greysen SR, Chretien KC, Kind T, Young A, Gross CP. Physician violations of online professionalism and disciplinary actions: A national survey of state medical boards. JAMA 2012; 307:1141-2. https://doi.org/10.1001/jama.2012.330.

8. Guseh JS 2nd, Brendel RW, BrendelDH. Medical professionalism in the age of online social networking. J Med Ethics 2009; 35:584-6. https://doi.org/10.1136/jme.2009.029231.

9. Gabbard GO, Kassaw KA, Perez-Garcia G. Professional boundaries in the era of the internet. Acad Psychiatry 2011; 35:168-74. https://doi.org/10.1176/appi.ap.35.3.168.

10. Greysen RS, Kind T, Chretien KC. Online professionalism and the mirror of social media. J Gen Intern Med 2010; 25:1227-9. https://doi.org/10.1007/s11606-010-1447-1.

11. Paice E, Heard S, Moss F. How important are role models in making good doctors? BMJ 2002; 325:707-10. https://doi.org/10.1136/ bmj.325.7366.707.

12. Farnan JM, Paro JA, Higa JT, Reddy ST, Humphrey HI, Arora VM. Commentary: The relationship status of digital media and professionalism: It's complicated. Acad Med 2009; 84:1479-81. https://doi.org/10.1097/ACM.0b013e3181bb17af.
13. Landman MP, Shelton J, Kauffmann RM, Dattilo JB. Guidelines for maintaining a professional compass in the era of social networking. J Surg Educ 2010; 67:381-6. https://doi.org/10.10 16/j.jsurg.2010.07.006.

14. Korda H, Itani Z. Harnessing social media for health promotion and behavior change. Health Promot Pract 2013; 14:15-23. https://doi.org/10.1177/1524839911405850.

15. Elkhayat H, Amin MT, Thabet AG. Patterns of use of social media in cardiothoracic surgery; Surgeons' prospective. J Egypt Soc Cardiothorac Surg 2018; 26:231-6. https://doi.org/10.101 6/j.jescts.2018.07.003.

16. Terrasse M, Gorin M, Sisti D. Social media, e-health, and medical ethics. Hastings Cent Rep 2019; 49:24-33. https://doi. org/10.1002/hast.975

17. Palacios-González C. The ethics of clinical photography and social media. Med Health Care Philos 2015; 18:63-70. https:// doi.org/10.1007/s11019-014-9580-y.

18. Appelbaum PS, Kopelman A. Social media's challenges for psychiatry. World Psychiatry 2014; 13:21-3. https://doi.org/10.10 02/wps.20085.

19. Chretien KC, Kind T. Social media and clinical care: Ethical, professional, and social implications. Circulation 2013; 127:1413-21. https://doi.org/10.1161/CIRCULATIONAHA.112.128017.

20. Derse AR, Miller TE. Net Effect: Professional and ethical challenges of medicine online. Camb Q Healthc Ethics 2018; 17:453-64. https://doi.org/10.1017/S0963180108080572.

21. Lagu T, Kaufman EJ, Asch DA, Armstrong K. Content of weblogs written by health professionals. J Gen Intern Med 2008; 23:1642-6. https://doi.org/10.1007/s11606-008-0726-6.

22. Taubert M. Social media in palliative medicine research: Jump into the cool water. BMJ Support Palliat Care 2018; 8:292-3. https://doi.org/10.1136/bmjspcare-2018-001620. 